\title{
Advances in phenology and harvest characterization of the Chilean Vitis sp. germplasm collection and its use in table grape breeding
}

\author{
Erika Salazar*, Viviana Durán, Carolina Araya, Miguel García, and Paola Barba \\ Instituto de Investigaciones Agropecuarias, Centro Regional La Platina. Av. Santa Rosa 11610, La \\ Pintana, Santiago, Chile
}

\begin{abstract}
Germplasm collection and characterization is essential for plant breeding. Chile holds a collection of 347 Vitis accessions at Instituto de Investigaciones Agropecuarias, La Platina, that have been successfully used to develop new table grape cultivars such as Maylen ${ }^{\circledR}$. Located in the central valley of Chile, a section of the Vitis collection was characterized for two consecutive seasons for phenology as well as fruit quality parameters at harvest. In terms of phenology, the collections can be grouped in four main clusters, with a higher representation of individuals at the middle and late timing. Fruit phenotyping showed significant differences among wine and table grapes for cluster and berry weight, seed number and fresh seed weight, polar and equatorial diameters, as well as the ratio among these parameters. Interestingly, rachis weight, a novel parameter associated with fruit storage capacity, did not show differences among groups. Other novel traits, such as the combination of commercial seedleesness and berry equatorial diameters above $2 \mathrm{~cm}$ were less represented, suggesting the need to create and introduce genetic variability for table grape breeding purposes.
\end{abstract}

\section{Introduction}

Phenology is described as one of the main factors to be explored for varietal adaptation and plays a major role in the distribution of current cultivars [1,2]. Grapevine phenology variability is particularly high and has been addressed in several studies at the species level [3]. Usually, growers use this information to 1) choose the variety that is more suitable to their vineyard, 2) adapt their practices (i. e. fertilization, topping) to variations in climatic conditions in space (among vineyards) and in time (among vintages), 3) coordinate logistics for harvesting, packing and cold house operations.

Currently in Chile 96 varieties are cultivated for wine production. However, only 7 wine varieties (Cabernet-Sauvignon, Carmenère, Merlot, País, Sauvignon Blanc, Syrah and Tintoreras complex) represent $71.1 \%$ of the total wine vines surface area (146,341 ha) [4].

\footnotetext{
*Corresponding author: paola.barba@inia.cl
} 
Diversity on cultivated table grapes is higher. With 541.312 Ton send overseas in 2019, Chile leads the global table grapes exportations. Although $83 \%$ of this volume corresponded to traditional varieties (Red Globe, Crimson, Thompson, Flame, Sugraone, Autumn Royal) the remaining 17\% was composed of over 30 licensed cultivars, such as Timco, Sweet Celebration, Arra15, Allison, Scarlotta, Pristine, Sable, Krissy and Maylen [5]. The superior productive and quality of new varieties makes them interesting for growers, even when some of them may not adapt to the climatic conditions in Chile, and requires payment of royalties.

In order to preserve and study traditional cultivars, and to develop new table grape varieties, INIA started a grapevine breeding program (PMG) and a Vitis germplasm collection in the 1980's. From the 347 accessions, 140 are naturalized grapevines collected from arid regions in Northern Chile [6]. At present, the PMG has internationally released Maylen ${ }^{\circ}$, a black seedless variety with both, extraordinary flavor and postharvest condition [7]. The germplasm collection is composed by 347 varieties, several of them with intravarietal clones. To better exploit this available biodiversity for breeding and research, further investigation is required. Here we describe phenological and phenotypic traits under Chilean central valley conditions, the main wine and table grape cultivation area [8].

\section{Materials and Methods}

\section{1 Plant material}

This collection is located at La Platina Research Center, La Pintana, Santiago, $33^{\circ} 34^{\prime} \mathrm{S}$, $70^{\circ} 37^{\prime} \mathrm{W}$, elevation $630 \mathrm{~m}$. Most vines are own-rooted and trained in an alternately Geneva double crosshead; with row and vine spacing of $3.0 \times 1.5 \mathrm{~m}$ and standard culture and phytosanitary practices. Plant growth regulators were not applied to these vines. Vines has been introduced and collected over time, representing the diversity for wine, table and raisin production.

\section{2 Phenology characterization}

The phenological characterization was conducted during the 2018-2019 and 2019-2020 growing seasons on 137 genotypes, a $62 \%$ of the entire collection, for the following stages: wool bud, budburst, green shoot, first leaf, unfolded leaves, inflorescence visible, inflorescence elongating, flower separating, beginning flowering, beginning flowering, full flowering, setting, small berries, berry touch, véraison beginning, full véraison, $100 \%$ véraison and harvest date.

Climatic data such as maximum (Tmax), minimum (Tmin) and medium (Tmed) temperatures and precipitation were obtained from la Platina meteorological weather station located at $100 \mathrm{~m}$ of the vineyard. These parameters were used to derive other variables relevant in viticulture studies, including thermal amplitude (cumulative daily air temperature difference - maximum minus minimum), and heat summation requirements, were observed for a growing degree-days base of $10^{\circ} \mathrm{C}\left(\mathrm{GDD}=\Sigma\left(\mathrm{T}>10^{\circ} \mathrm{C}-10^{\circ} \mathrm{C}\right)\right)$. The location is representative of the climatic conditions of the Chilean central valley, the main wine and table grape cultivation area, with 135,631 and 8,871 hectares, respectively [8]. The obtained data were processed by uni- and multivariate statistical analysis by using InfoStat program. Ward method and Euclidea distances was used for cluster identification. 


\section{3 Cluster and berry phenotyping}

A subset of 138 cultivars were selected for cluster and berry phenotyping during seasons 2017-2018 and 2018-2019. Up to three vines per genotype were used. For each vine three clusters were harvested when soluble solids reached between 16 to $18{ }^{\circ}$ Brix. Ten random berries for cluster were selected for following measurements: berry weight $(\mathrm{g})$, number of seeds per berry, fresh seed weight $(\mathrm{g})$, sugar content $\left({ }^{\circ} \mathrm{Brix}\right)$, polar and equatorial diameters $(\mathrm{cm})$. Berry shape was calculated as the ratio between polar and equatorial diameters. Complete clusters were weighted (g), and after removal of all berries, rachis were weighted (g). Genotype utilization was assigned according to the Vitis International Variety Catalogue VIVC [9] in the categories: Table, Wine and Both. For each trait, significance of differences between groups were determined using a Kruskal-Wallis rank sum test implemented in R [10].

\section{प. Results and Discussion}

\section{1 Phenology characterization}

The phenological monitoring of the states such as: green shoot, first leaf, unfolded leaves, inflorescence visible, inflorescence elongating, flowers separating, beginning flowering, full flowering, setting, small berries, berry touch, véraison beginning, full véraison, $100 \%$ véraison and harvest has been carried out until the harvest moment during the 2018-2019 and 2019-2020 seasons (Figure 1), presenting variability among different cultivars in the same growing season, buy also differences in the accession's phenology between the two seasons. In 2018, wool bud started in July 13th for 13 cultivars, represented mainly by wine varieties. In 2019 wool bud of 45 varieties started in July 29th. There is an interval of 59 and 54 days between the earlier and the varieties that begins later this phenological state in 2018 and 2019, respectively.

According two-season phenological data table grapes can be grouped in four main clusters, with significant differences in all evaluated stages: the earlier group, harvested in 177 Julian days (February), includes only 2 varieties while the later one grouped 5 varieties mainly were harvested in 222 Julian days (March). Wine grapes were grouped in three clusters: the earlier group represented by 21 varieties harvested among 188 Julian days (February); the later varieties, represented by 39 varieties were harvested between 200 Julian days (April).

Most of the varieties of the INIA germplasm collection are classified in the medium category class in terms of timing of flowering and véraison. Very early and very late phenology classes are underrepresented (Figure 2).

\section{2 Harvest characterization}

As it has been previously described, wine and table grapes are genetically and phenotypically different $[11,12]$. On average, table grapes of the INIA collection have heavier clusters $(546.4 \mathrm{~g}$ vs $319.8 \mathrm{~g}$, p-value $<0.0001)$, composed of heavier $(4.44 \mathrm{~g}$ vs $2.00 \mathrm{~g}$, p-value $<0.0001)$, bigger $(1.77 \mathrm{~cm}$ vs $1.41 \mathrm{~cm}$, p-value $<0.0001)$ and more elongated berries $(1.22$ vs $1.11 \mathrm{BRP} / \mathrm{BRE}$, p-value $<0.0001)$ than wine grapes. Wine grapes have significantly more seeds per berry $(2.16$ vs 1.69 ; p-value $=0.0001)$ and higher fresh seed weight $(1.24 \mathrm{~g}$ vs $0.72 \mathrm{~g}$, p-value $<0.0001)$ than table grapes. Among the eight traits measured at harvest, only rachis weight was not significantly different among grapevine categories ( $\mathrm{p}$-value $=0.826$ ), with an average value of $12.45 \mathrm{~g}$ (Figure 3 ). 
The relationship between fresh seed weight and equatorial diameter was further explored to identify potential parental materials (Figure 4).

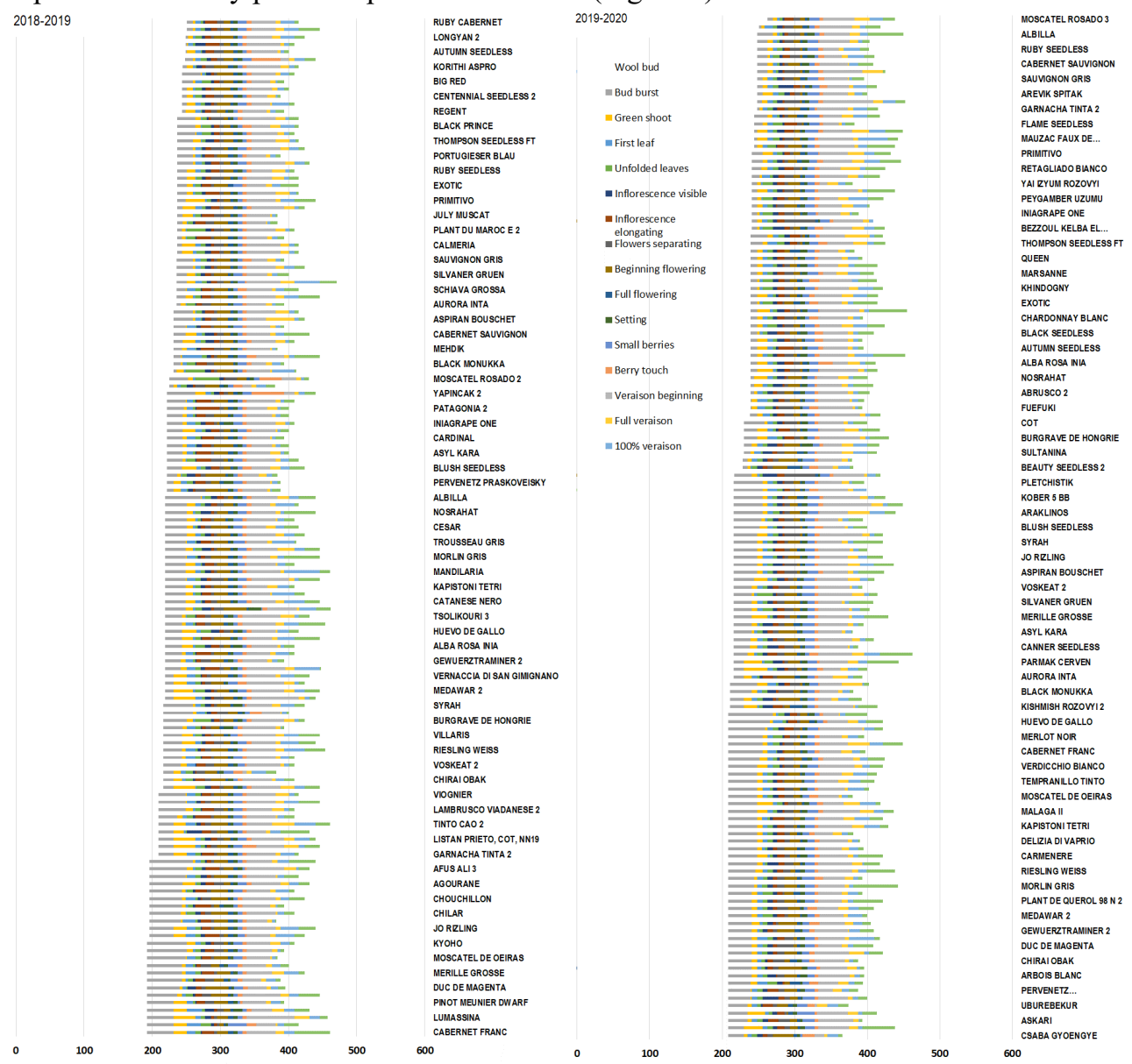

Fig. 1. Phenologycal variability among cultivars observed during 2018-2019 and 2019-2020 growing season. In the phenograms, the color changes represent different growing stages. DOY: Day of a year.
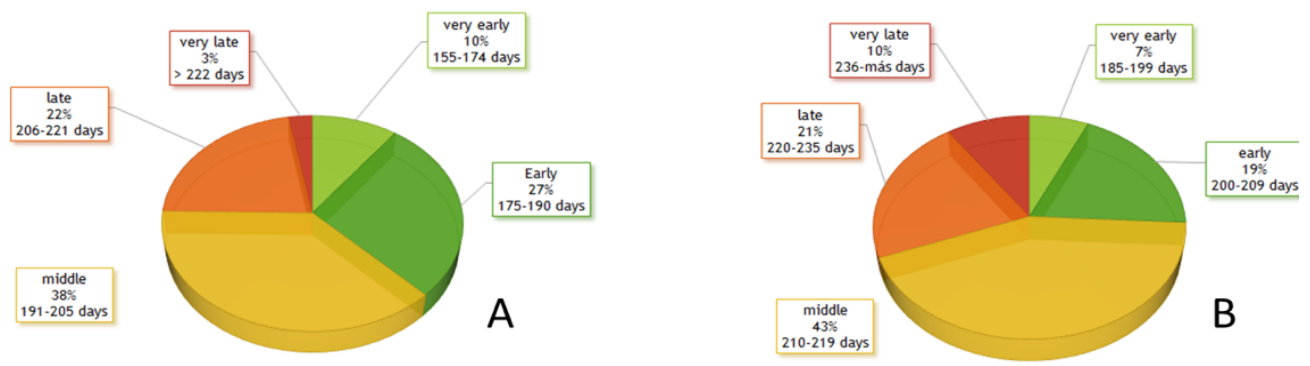

Fig. 2. Category class composition of the germplasm collection evaluated in terms of timing of flowering (A) and véraison (B). Data shown for 2018-2019 growing season. 

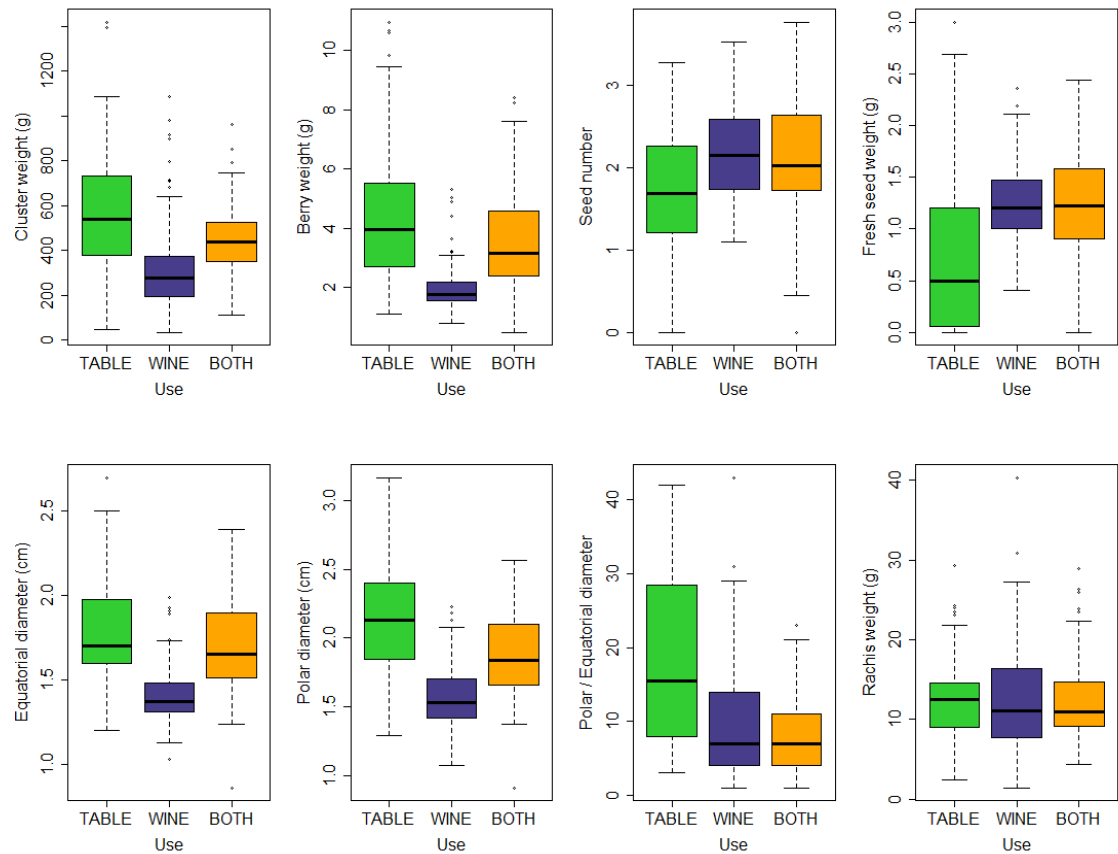

Fig. 3. Harvest phenotype distribution by grape use. Averaged season values (2017-18 and 2018-19) were used for each genotype form INIA Vitis collection $(\mathrm{n}=138)$. For each data set, the box indicates the range between 25 and $75 \%$, and middle band indicated the sample median.

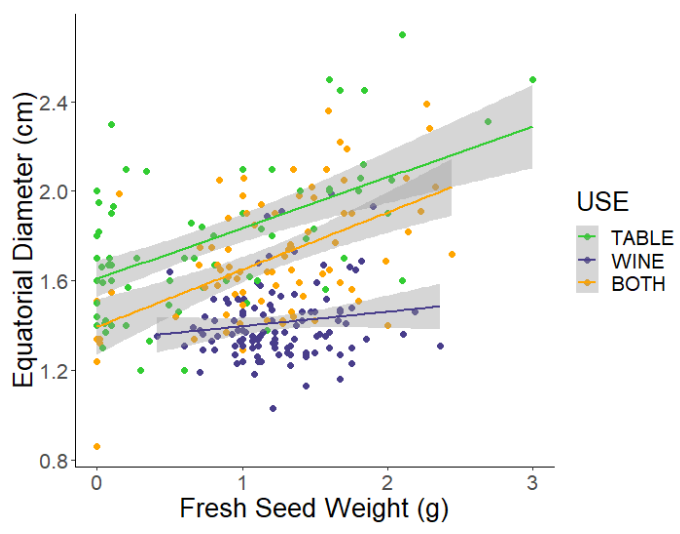

Fig. 4. Relationship between fresh seed weight and berry equatorial diameter according to grape use. Averaged season values (2017-18 and 2018-19) were used for each genotype form INIA Vitis collection $(\mathrm{n}=138)$.

When developing or introducing new grape varieties, the phenology and ripening monitoring is important in determining the ability of a region to produce a quality crop within the confines of its climate regime. In this study the phenology and harvest characterization of table and wine varieties were monitored, in order to characterize their adaptation under the Central Valley climatic conditions.

Time between phenological stages varies greatly with grapevine variety, climate, and geographical location $[13,14]$. Our preliminary results allowed us to compare sensitivity to temperature change among varieties, but also varieties behavior among seasons. Cabernet 
Franc, Romorantin, Villaris and Cabernet Franc showed the major differences in time between wool bud to harvest with 64, 61, 52 and 51 days among seasons, respectively. Chardonnay Blanc, Chilar, Garnacha Tinta, Isabella had the same behavior in both seasons. Differences on climatic parameters between evaluated seasons were observed mainly for Tmax, Tmin, moderate hot days, extreme warm events. The maturation period of the 20182019 season had higher temperature values in relation to the 2019-2020 season, resulting in higher GDD values (data not shown).

At harvest, table and wine grapes showed significant differences associated to its use for all traits related with cluster and berry composition, which agree with previous literature [11]. This relationship was not significant for rachis weight, a trait of relative recent relevance for its relation with postharvest condition of the fruit, likely because it has not been selected during the grapevine domestication process.

New commercial table grapes varieties have introduced several traits for consumers and producers. Among these, the most common are elongated, seedless berries that can be obtained with minimal application of exogenous growth promoters, such as gibberellic acid (GA3). Although a positive correlation between fresh seed weight and natural berry weight or equatorial diameter has been described [15], there are remarkable examples of commercial seedless grapes with natural diameters above $2 \mathrm{~cm}$. This type of outlier individuals was not frequent in the germplasm studied, suggesting that breeding programs in Chile could need to introduce this type of materials, as well as early-mature types.

\section{Conclusion}

Phenology and harvest characterization of the Vitis sp. germplasm collection in Chile was performed on 347 accessions for two seasons. Four groups were identified according to the time of phenology from wool bud to ripening date. In terms of harvest, fruit from table or wine grapes had significant differences for most of the traits studied, except for rachis weight. The combined data allowed to identify accessions with outlier phenotypes relevant for table grape quality breeding. According to these results, plant internment efforts are necessary in order to maximize the phenotypic diversity of the collection in traits like ripening date (prioritizing late and early varieties), berry size and shape.

The authors acknowledge funding from: UC-Davis Chile DiveVid Project (13CEI2-21852); INIA/MINAGRI project: 501453-70 and 500495-70; Innova-CORFO project: 09PMG-7229 and FONDECYT 11161044.

\section{References}

1. E. Duchêne, F. Huard, V. Dumas, C. Schneider, D. Merdinoglu, Clim. Res., 41, 193204 (2010). https://doi.org/10.3354/cr00850

2. I. García de Cortázar-Atauri, E. Duchene, A. Destrac-Irvine, G. Barbeau, L. de Rességuier, T. Lacombe, A.K. Parker, N. Saurin, C.s van Leeuwen, OENO One, 51, 115-126 (2017). https://doi.org/10.20870/oeno-one.2017.51.2.1622

3. A. Parker, I. García de Cortázar-Atauri, I. Chuine, G. Barbeau, B. Bois, J.-M. Boursiquot, J. Y. Cahurel, M. Claverie, T. Dufourcq, L. Gény, G. Guimberteau, R. W.Hofmann, O. Jacquet, T. Lacombe, C. Monamy, H. Ojeda, L. Panigai, J. C. Payan, B. R. Lovelle, E. IRouchaud, C. Schneider, J. L. Spring, P. Storchi, D. Tomasi, W. Trambouze, M. Trought, C. van Leeuwen, Agric. For. Meteorol., 180, 249-264 (2013). https://doi.org/10.1016/j.agrformet.2013.06.005 
4. SAG. Catastro Vitícola Nacional (2018). http://www.sag.cl/ambitos-deaccion/catastro-viticola-nacional/1490/publicaciones

5. ASOEX (2019). https://www.asoex.cl/estadisticas-de-exportacion.html (2019)

6. A. Milla-Tapia, S. Gómez, X. Moncada, P. León A. Ibacache M. Rosas B. Carrasco P. Hinrichsen A. Zurita-Silva, Aust. J. Grape Wine Res., 19(2), 299-310 (2013). https://doi.org/10.1111/ajgw.12020

7. C. Uquillas, E. Torres, A. Ibacache, B. G. Defilippi, HortScience, 48, 501-503 (2013). https://doi.org/10.21273/HORTSCI.48.4.501

8. G. Rojas, The wine-growing geography of Chile (Vinifera, Santiago de Chile, 2019). https://vinifera.cl/documentos/THE_WINE_GROWING_AND_GEOGRAPHY_OF_C HILE_By_VINIFERA_2019.pdf

9. Vitis International Variety Catalogue VIVC. https://www.vivc.de/

10. R Core Team (2013). http://www.R-project.org/

11. S. Myles, A. R. Boyko, C. L. Owens, P. J. Brown, F. Grassi, M. K. Aradhya, B. Prins, A. Reynolds, J. M. Chia, D. Ware, C. D. Bustamante, E. S. Buckler, Proc. Natl. Acad. Sci. USA. 108(9), 3530-3535 (2011). https://doi.org/10.1073/pnas.1009363108

12. Z. Magicovsky, J. Sawler, K. M Gardner, M. K Aradhya, B. H. Prins, H. R Schwaninger, C. D Bustamante, E. S. Buckler, G. Y. Zhong, P. J Brown, S. Myles, Hort Res., 4, 17035 (2017). https://doi.org/10.1038/hortres.2017.35

13. A. Alikadic, I. Pertot, E. Eccel, C. Dolci, C. Zarbo, A. Caffarra, R. De Filippi, C. Furlanello, Agric. For. Meteorol., 271, 73-82 (2019). https://doi.org/10.1016/j.agrformet.2019.02.030

14. D. Tomasi, G. V. Jones, M. Giust, L. Lovat, F. Gaiotti, Am. J. Enol. Vitic., 62(3), 329339 (2011). http://doi.org/10.5344/ajev.2011.10108

15. N. Mejía, B. Soto, M. Guerrero, X. Casanueva, C. Houel, M. de los Ángeles Miccono, R. Ramos, L. Le Cunff, J.M. Boursiquot, P. Hinrichsen, A.F. Adam-Blondon, BMC Plant Biol., 11, 57 (2011). https://doi.org/10.1186/1471-2229-11-57 